\title{
MIDAS
}

Museus e estudos interdisciplinares

$4 \mid 2014$

Varia e dossier temático: "Museus, utopia e urbanidade"

\section{Módulos com maior porosidade em relação à comunidade: Uma sugestão para centros de arte contemporânea}

Modules with porosity within the community: A suggestion for contemporary art centres

\section{Catarina Marto}

\section{(2) OpenEdition}

\section{Journals}

\section{Edição electrónica}

URL: http://journals.openedition.org/midas/695

DOI: 10.4000/midas.695

ISSN: 2182-9543

\section{Editora:}

Alice Semedo, Paulo Simões Rodrigues, Pedro Casaleiro, Raquel Henriques da Silva, Ana Carvalho

\section{Refêrencia eletrónica}

Catarina Marto, « Módulos com maior porosidade em relação à comunidade: Uma sugestão para centros de arte contemporânea », MIDAS [Online], 4 | 2014, posto online no dia 13 março 2015, consultado no dia 01 maio 2019. URL : http://journals.openedition.org/midas/695 ; DOI : 10.4000/ midas.695

Este documento foi criado de forma automática no dia 1 Maio 2019.

\section{cc) (†) (2)}

Midas is licensed under a Creative Commons Attribution-NonCommercial-ShareAlike 3.0 International License 


\section{Módulos com maior porosidade em relação à comunidade: Uma sugestão para centros de arte contemporânea}

Modules with porosity within the community: A suggestion for contemporary art centres

\section{Catarina Marto}

NOTA DO EDITOR

Artigo recebido a 04.04.2014

Aprovado para publicação a 16.10.2014

Assim, a diferença entre autor e público está prestes a perder o seu caráter fundamental.

(Benjamin 1992)

Devíamos pensar mais um pouco sobre a vocação comunitária do homem que é, como as formigas e

as abelhas, um dos raros animais que vive em sociedade organizada. O que acontece é que pertenço a uma geração que talvez tenha chegado ao topo do individualismo neste vaivém da história entre o individual e o coletivo. Sinto muito profundamente estes dois apelos, o de estar só e o de viver numa comunidade. Tenho dias e, sobretudo, sinto uma incapacidade visceral de ser definitivamente uma coisa e outra. (Baptista 1988) 
Une communauté émancipée est une communauté de conteurs et de traducteurs. (Rancière 2008)

10 projeto "Téléthèque: Encontros Videográficos" (daqui em diante apenas Téléthèque), que organizámos no âmbito da Plataforma Ma, juntamente com Aida Castro e Maria Mire, é o objeto de análise deste artigo. ${ }^{1} \mathrm{Na}$ sequência deste projeto acumulou-se documentação, ligações, reflexões e algumas pistas de investigação. Assim, a partir de problemas levantados pelo vídeo na arte contemporânea, levantam-se diferentes problemáticas (o visitante, a desmaterialização, a conservação), numa tentativa de pensar a exposição e o papel da museologia contemporânea.

2 No presente texto explora-se sobretudo a noção de "encontros" do ciclo Téléthèque. Na primeira parte, após uma breve descrição de Théléthèque, procura-se explicar o que motivou o projeto. Na segunda parte, estabelecem-se paralelos com outros projetos de curadoria observados logo após a realização de Théléthèque e no seguimento de uma viagem a Paris. Por fim, a reflexão toma contornos um pouco mais teóricos e abre-se a um campo que extravasa o da museologia e o da arte contemporânea.

\section{I - A concepção de Téléthèque como resposta contextual}

3 Téléthèque consistiu em nove sessões de conversa, em torno de obras em vídeo, com o respetivo autor e um convidado. Com a cadência aproximada de uma sessão mensal, entre janeiro e novembro de 2010, as conversas tiveram lugar num espaço peculiar e homónimo, a Téléthèque, mais especificamente o estúdio 2, nas instalações do Institut Français du Portugal, em Lisboa. ${ }^{2}$

$\mathrm{O}$ conceito Téléthèque, cuja definição é «local onde são conservados os arquivos de gravações da televisão» (Le Nouveau Petit Robert 1993, 2223, tradução da autora) é recente (de 1967) mas, já datado, teve pouco uso. O espaço físico, igualmente obsoleto, muito gentilmente cedido pelo Institut Français du Portugal, através da colaboração de JeanPaul Lefèvre, foi, aliás, entretanto totalmente remodelado. $O$ projeto Téléthèque foi desenhado a partir do próprio espaço, pelas suas características: o conforto acolhedor do mobiliário e a alcatifa alaranjada que revestia o chão e as paredes da sala, a excelente projeção de voz que oferecia, e o monitor com boa qualidade de imagem, suspenso na parede, parecendo estar ali esquecido há décadas. Este décor já não existe. Mas não só de décor se tratou Téléthèque, pois este ciclo foi desenhado cuidadosamente respondendo a diversas constatações e intuições. Intuições essas que correspondem às profundas alterações em diferentes áreas do campo das artes visuais e da museologia, em geral. Essas alterações aconteceram a vários níveis: na postura do público, cada vez mais um elemento a ter em conta, com uma voz informada; nos suportes e nos espaços de apresentação da arte, na sua desmaterialização; no crescente protagonismo do discurso verbal nas artes visuais; e também nos diferentes paradigmas relacionados com a proliferação dos meios e ferramentas digitais, nas suas possibilidades e limitações. 
Fig. 1 - 0 estúdio 2 (Téléthèque)

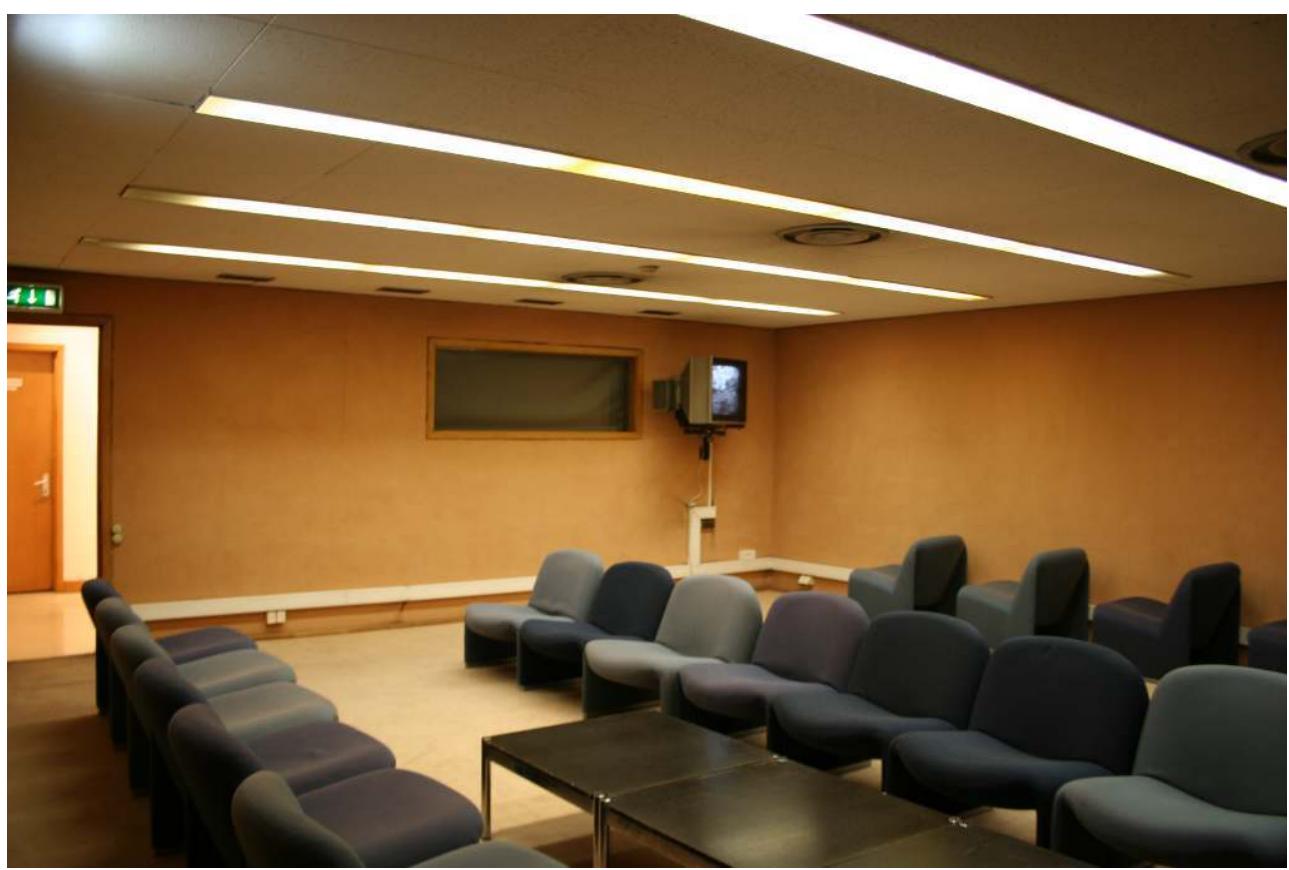

NO INSTITUT FRANÇAIS DU PORTUgAL (LISBOA), EM 2010 (ANTES DA SUA REMODELAÇÃO) DISPOSITIVO \#1 (ESPAÇO dE VISIONAMENTO) AO FUNDO À DIREITA, DISPOSITIVO \#2 (ESPAÇO DE CONVERSA) À ESQUERDA

(C) CATARINA MARTO

Por outro lado, houve ainda a perceção que, na altura, os numerosos eventos sucediam-se, em contextos frágeis (não institucionais e com poucos ou nenhuns meios) sem que, muitas vezes, houvesse uma reflexão sobre os mesmos e, para os criadores, sem um real retorno ou diálogo sobre as suas criações que, de seguida, desapareciam no excesso de imagens e informação, tornando, por vezes, o que é um ato laborioso e especializado, em algo de inconsequente e frustrante. Esta ausência de discurso pode tornar-se desanimadora em termos criativos e de estímulo de trabalho.

Detetou-se ainda outro problema, este relacionado com a memória: o que acontece a obras efémeras e/ou contextuais, ou mesmo ao seu registo uma vez terminada a exposição (o que pode ser hoje um problema pelo excesso de informação não organizada), numa área dinâmica, mas com uma escassez de meios inexplicável e com uma produção prolífica. A tudo isto, acrescente-se o problema de conservação e de registo que levantam certas obras (site specific, efémeras, digitais, entre outras) problemática na ordem do dia, à qual a comunidade museológica tem procurado encontrar respostas e estratégias.

7 A questão fundamental, neste contexto, e que diz respeito a todos os atores na área, principalmente a colecionadores e artistas, é: como conservar, para efeitos de arquivo ou coleção, obras de arte efémeras, interativas ou em suportes que se tornam rapidamente obsoletos? A questão será mais exatamente: como reproduzir obras cuja existência matérica é instável ou variável (em oposição às peças estáveis da escultura em pedra por exemplo)? A ideia de "reativar uma obra" traduz claramente o que está em jogo.

8 Sucintamente, sobre esta matéria, três conceitos surgem repetidamente em diferentes testemunhos ${ }^{3}$ : a emulação (em vez de se restaurar um mesmo objeto com um programa obsoleto e inacessível, reconstitui-se o efeito produzido por esse objeto com meios atuais, 
imitando o comportamento de outro tipo de equipamento ou programa.); o guião ou partitura, tomando exemplo na partitura da música (os concertos do século XVIII eram efémeros, mas ainda os podemos recriar), um documento criado pelo artista substitui a obra a ser recriada a cada apresentação seguindo as indicações do artista); o questionário (que permite entender as intenções do artista e claro a documentação da obra - imagens, registos áudio, e textos - como apoio para a sua recriação: «(...) visant à déterminer comment les artistes aimeraient voir leurs oeuvres recrées à l'avenir» (Depocas, Ippolito e Jones 2003, 47). De salientar que, quanto mais profundo for o conhecimento sobre uma obra e artista, provavelmente maior será fidelidade da reconstituição. Trata-se de, por vezes, explorar descrições da obra independentemente do medium. Estes novos conceitos de conservação e restauro induzidos pelos novos medias e linguagens adotadas na arte contemporânea têm por consequência diversos fatores, como por exemplo: o comissário terá um importante papel de intérprete da obra (como na música se interpreta uma partitura), a sua sensibilidade, a sua cultura e criatividade estão em jogo; leva também a que, segundo Richard Gagnier, haja um deslize na área da conservação, do conceito de autenticidade (no qual o que conta é o original, as componentes físicas, a inscrição histórica, na tradição ocidental) para o de integridade (em que as noções a respeitar são: função, conceito, significado das componentes físicas, comportamento, experiência do espectador, estética) (Gagnier 2014).

$\mathrm{Na}$ "documentação da arte", uma missão de museus e de colecionadores, procura-se a "sistematização" da informação, a uniformização de formatos e de protocolos, no sentido da informação poder ser integrada em programas informáticos e partilhada. Procura-se idealmente estabelecer protocolos comuns (internacionais) no sentido de desenvolver bases de dados interconectáveis. A documentação da arte pode contar ou não com a colaboração dos criadores.

10 A sistematização da informação a este nível parece indispensável. No entanto, a complexidade dos sistemas e o seu caráter mecânico/digital pré-programado podem causar alguma reticência. Não será uma grande parte da eficácia e justeza da reconstituição/apresentação duma obra dependente do conhecimento profundo da obra em questão (seu contexto histórico, percurso do artista) e da sensibilidade do curador, sua intuição, formação e percurso?

Il nous parait essentiel que l'art de la fin du XXe siècle et les nouvelles pratiques artistiques fassent l'objet d'une compréhension et d'une contextualisation par voie de conversations avec les artistes, dont les commentaires critiques informent et élargissent notre compréhension de la culture visuelle. (Depocas, Ippolito e Jones 2003, 8)

11 Na fase de conceção do projeto Téléthèque, constatou-se ainda que, paradoxalmente, face à profusão e multiplicação de meios de registo e comunicação, havia a necessidade de selecionar e filtrar material, tratar a informação e criar uma narrativa (uma história). De maneira geral, a questão então colocada foi: para quê fazer e ver exposições desenfreadamente, se não se tenta dar um sentido a esta atividade e construir um discurso? A Téléthèque foi uma tentativa de resposta a todas estas observações intuídas e, neste sentido, um intervalo da ação para os criadores.

Depois, no decorrer de Téléthèque, foi-se tornando mais clara a necessidade e a pertinência do diálogo, da reflexão em coletivo e ao vivo (presencial). No aprofundamento da compreensão dos trabalhos dos artistas e da reflexão de outros intervenientes na área da arte contemporânea, no estímulo que se revelou ser para a criação, na partilha de 
ideias e referências e experiências. Existem numerosos exemplos de outros eventos com características muito similares (vamos analisar alguns mais à frente). Não será este tipo de iniciativa, algo a reinventar, sempre, em adequação às necessidades, aos contextos e aos meios de que se dispõe? Antes dos exemplos que se podem multiplicar, ficam desde já alguns apontamentos e questões.

Após a última sessão da Téléthèque (que já decorreu há mais de três anos), com o entusiasmo ainda a quente, prevaleceu a ideia seguinte: porque não tornar a catalogação de uma obra, num evento coletivo e público, parecido com o que vivemos na Téléthèque? Questionar o artista, o colecionador e o público em relação ao essencial de uma obra, discutir e expor as diferentes interpretações e perceções, multiplicar os pontos de vista não caminha a História da Arte neste sentido também? Num distanciamento e reflexão historiográficos, no reconhecimento da multiplicidade de discursos e versões consoante a origem, o género, a época do historiador ou do testemunho e ponto de vista adotado - isto especialmente nos casos em que a obra será guardada por uma instituição pública. Uma utopia? E, dadas as características "variáveis" dos suportes das obras atuais, os testemunhos das diversas leituras da obra tornam-se preciosos para o seu entendimento plural e para uma sua eventual reconstituição futura. Podemos dizer que essa diversidade de testemunhos é o que atribui sentido e finaliza as obras "variáveis", completando o seu ser...?

\section{II - Da necessidade de instaurar os centros de arte contemporânea como ponto de encontro: alguns exemplos}

Noutra área da museologia, na área dos museus de identidade, Paul Rasse fez uma interessante e completa reflexão sobre a presença da comunidade em geral na construção de museus de sítio em Techniques et Cultures au Musée: Enjeux, Ingéniérie et Communication des Musées de Société (1997), que se deveria ter também em conta nos centros de arte contemporânea. Não é suposto o centro de arte contemporânea tratar da arte que se produz no momento presente e, portanto, ser um edifício a tecer em conjunto com a comunidade local (tal como o que Rasse preconiza para os museus de sítio - tema a que voltaremos mais adiante), constituída tanto pelo público como pelos criadores? Não deve o centro de arte contemporânea ser pensado como um ponto de encontro privilegiado em torno do que é a sua essência, a arte contemporânea? Não deveriam ser os criadores o foco deste tipo de instituição ou, pelo menos, ser-lhes dado um espaço considerável na instituição e até na determinação do que deve ser uma instituição deste género e o tipo de atividades a desenvolver? Como fazer existir o artista em carne e osso, no interior da instituição? Pois estão vivos e ativos (e é um privilégio alheio a museus de arte e património do passado). 0 centro de arte contemporânea tornar-se-ia, desta forma, uma instituição mais viva e dinâmica e, então sim, verdadeiramente contemporânea, ou seja, com vocação para tratar da arte do seu tempo, do presente.

Existem numerosos exemplos em que tal é praticado, ainda que sob diferentes formas. Houve em 2011, por exemplo, o projeto "Outros Olhares Novos Projetos", no Museu Nacional Arte Contemporânea - Museu do Chiado, em que artistas foram convidados a comentarem elementos específicos da coleção com uma criação original e um texto. Um dos centros pioneiros deste tipo de abordagem terá sido o Centre Georges Pompidou, com 
o seu primeiro diretor, Pontus Hulten: «O museu converteu-se num ponto de encontro para toda uma geração» (Obrist 2010, 44). Atualmente, com iniciativas continuadas como Vidéos et Après (existe um catálogo homónimo, veja-se Assche 1992), um ciclo de projeções (uma sessão por mês) apresentado da seguinte forma: ${ }^{4}$

Vidéos et Après traz um olhar vivo sobre a coleção. Um encontro que tem lugar uma segunda-feira por mês. As programações são orientadas segundo diferentes eixos: sessões temáticas, monografias de artistas, ou ainda sessões relacionadas com a atualidade cultural. As sessões realizam-se com a presença de artistas, críticos ou historiadores de arte. Algumas sessões encontram-se disponíveis no website do Centre Pompidou. (texto de sala da coleção Nouveaux Médias do Centre Pompidou, tradução da autora)

Existem no Centre Pompidou outras iniciativas temporárias de interesse, relacionadas com a integração da criação contemporânea e seus atores no espaço físico da instituição. Detenhamo-nos um pouco na exposição/sala de projeção/teatro científico Æther, uma proposta do artista alemão Christoph Keller para o Nouveau Festival du Centre Pompidou, que decorreu entre 16 de fevereiro e 7 de março 2011. Este projeto de curadoria permitia a coexistência num mesmo espaço (Espace 315, uma sala ampla, com mais de $300 \mathrm{~m}^{2}$ ) de uma exposição e um auditório, este último com a dupla função de plateia para um ecrã de projeção (com sessões de projeções de obras diferentes, todos os dias às 17h30) e para conferências (um convidado escolhia e comentava uma obra, todos os dias às $14 \mathrm{~h}$ ), em torno do conteúdo temático proposto: o éter e estados de consciência alterados. 0 título desta exposição aponta para o que está em causa: uma forma de dar espaço ao invisível e intangível, visioná-lo e pensá-lo. Em Æther, uma exposição de um artista-comissário, tal aconteceu de diferentes formas, ao instaurar-se na sala de exposição uma dinâmica de proximidade entre o público, os convidados (artistas, conservadores, historiadores, cientistas) e as obras expostas, ou ao provocar um cruzamento de diferentes áreas de saberes, apontando para metodologias e campos comuns à ciência, à filosofia e humanidades, e à arte. $\mathrm{O}$ próprio Christoph Keller, enquanto artista e tendo uma formação base na área das ciências, conjuga todos estes elementos. A entrada nesta área do Centre Pompidou é gratuita, o que possibilitou a participação do público nas numerosas atividades propostas no projeto Æther, integrado no programa Le Nouveau Festival du Centre Pompidou. 
Fig. 2 - Centre Pompidou, exposição AEther (2011)

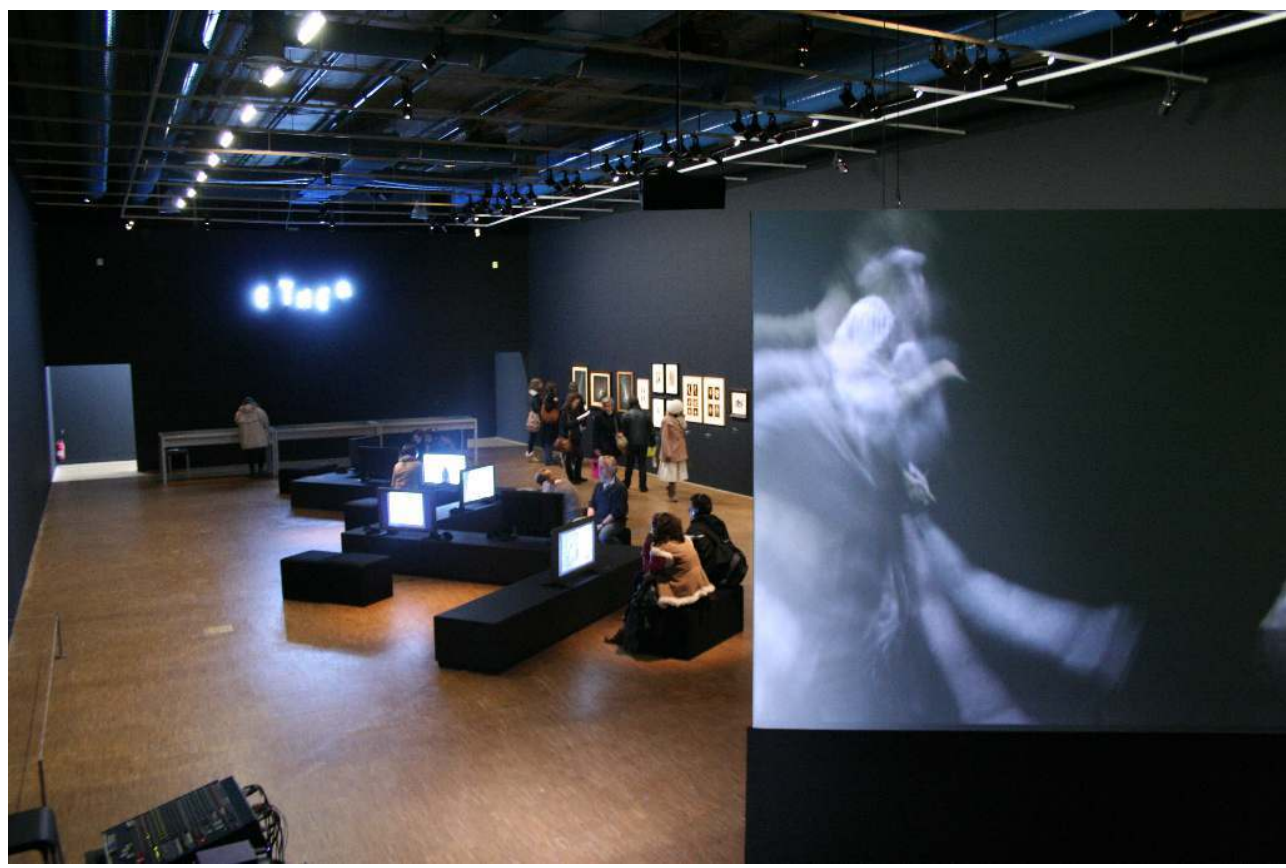

SALA DE EXPOSIÇÃo COM OBRAS DE PAREDE, EM VITRINE, VÍDEOS EM CONSULTA NO CENTRO E 0 AUDITÓRIO COM ECRÃ DE PROJEÇÃo

(C) CATARINA MARTO

Fig. 3 - Centre Pompidou, exposição Ather (2011)

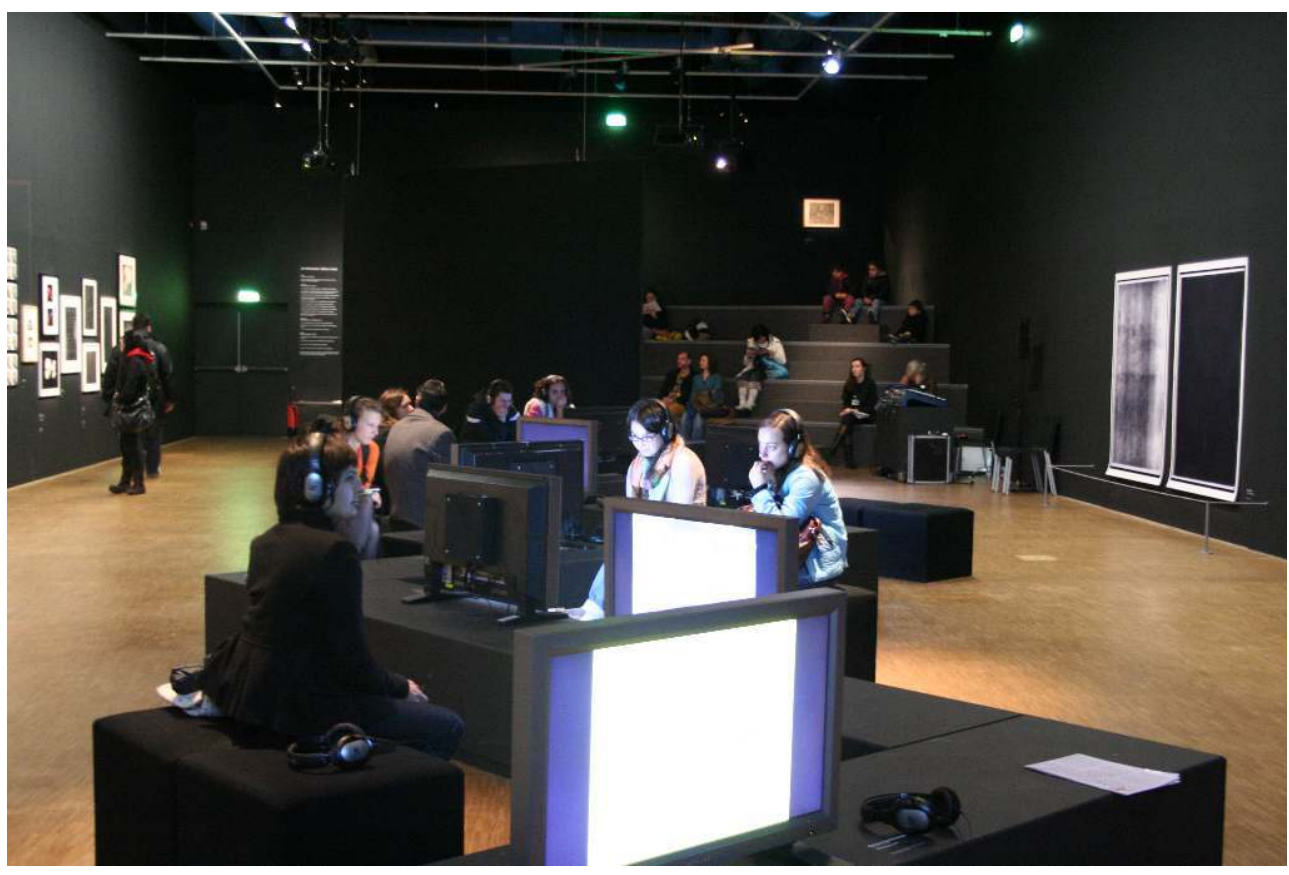

(C) CATARINA MARTO

17 Outra instituição, ainda em Paris, o Palais de Tokyo, dedica-se «[...] desde a sua abertura, à aproximação dos públicos à criação contemporânea francesa e internacional» (Palais de Tokyo 2014, s/p, tradução da autora). As características morfológicas deste espaço 
arquitetónico ajudam (áreas imensas num edifício despojado, "reciclado" para o efeito, com investimento minimal na sua adaptação). Obras mais experimentais puderam e podem ali expandir-se, sem restrições e testar a sua operacionalidade. Este centro organiza igualmente residências, "Pavillon Neufize OBC, Laboratoire de création du Palais de Tokyo". Na apresentação das residências o artista e diretor do projeto, Ange Leccia sublinha:

Desde o início dos anos 1980, o meu próprio percurso artístico levou-me a usufruir de numerosas bolsas de residências no estrangeiro que, na maioria das vezes, ficaram marcadas pela solidão. Esse isolamento veio alimentar o meu trabalho, mas também me demonstrou a importância dos encontros. Desta forma, o Pavillon foi concebido, antes de mais, como um local de partilha, um espaço de trocas e de debates. Acredito na necessidade de abertura ao outro e de comunicar. (...) Se cada artista desenvolve, claro está, um território singular, este só existe graças a este tipo de confronto. (Leccia 2011, s/p, tradução da autora)

Esta declaração vem corroborar a ideia da necessidade de criar espaços de diálogo e de encontro (confronto), na arte contemporânea, tanto para suprir uma eventual solidão, como forma e condição de fazer existir a sua singularidade.

Os meios financeiros (avultados ou escassos) não parecem ser um travão ou um acelerador desmedido para uma instituição próxima da criação contemporânea, com uma estrutura orgânica de sede com diversos polos, que se adapta e explora as condições de que dispõe e que vai conseguindo, concentrando-se no essencial da sua atividade, sem atribuir importância excessiva a condições de conforto ideais ou de representação social excessivas e desnecessárias. Não esqueçamos que o contexto social e a escassez de meios em França não são as mesmas do que em Portugal onde, no entanto, parece persistir, nalguns casos, um pudor institucional em operar duma forma pragmática e flexível (e eficaz), "a partir do que se tem", pondo de parte um certo jogo de aparências e representações que, por vezes, é um travão injustificado da ação. De uma forma geral, os centros de arte que desenvolvem um diálogo de proximidade com atores da criação contemporânea, cuja linguagem cada vez mais necessita deste tipo de contexto, não são novidade e têm vindo a multiplicar-se. Para citar apenas alguns que são disso uma tentativa e exemplo, em Lisboa, a Galeria Zé dos Bois tem um percurso marcante e, entre os mais recentes, o Carpe Diem Arte e Pesquisa, aberto há cinco anos.

Igualmente em Lisboa, entre 2000 e 2001, teve lugar uma série de exposições no Project Room, um espaço no Centro Cultural de Belém, atual Museu Berardo, programadas por Jürgen Bock, diretor da Maumaus - Escola de Artes Visuais. Estas exposições assumiram um caráter site specific, com obras e formas de expor adaptadas e pensadas para o contexto de apresentação, tendo em atenção a morfologia espacial, o seu estatuto simbólico enquanto polo histórico e a situação ribeirinha - considerando que se trata de «um lugar com ressonâncias psicológicas próprias» (Bock 2002, 19). O Project Room quis-se construído a partir de um estreito diálogo entre o artista, o curador, os atores locais e, desejavelmente, o público. Deste conjunto de exposições resultou o livro Da obra ao Texto, Diálogos Sobre a Prática e a Crítica na Arte Contemporânea, no qual o curador explica a reflexão subjacente ao projeto:

Envolvido pela enorme infraestrutura do $\mathrm{CCB}$, o Project Room procurou afirmar-se como área reservada para práticas artísticas que revelassem a sua especificidade num espaço de pequenas dimensões, oferecendo aos visitantes a possibilidade de "estudarem" os projetos numa atmosfera íntima, concentrada e "não espetacular". (Bock 2002, 14) 
21 A conjugação de projetos de diferentes escalas que envolvem diferentes processos de perceção da parte do público pode ser benéfica neste tipo de mega estruturas (p. ex. o Centro Cultural de Belém, atual Museu Berardo), em que o público se pode sentir desamparado ou mesmo "exausto" (expressão a que Jürgen Bock recorre mais adiante no texto), pela rotação de exposições de grande escala, no gigante white cube impessoal e "liso" (na aceção Deleuziana do termo).

22 A série de exposições do Project Room conduziu à organização de uma conferência final, aberta ao público, onde se reuniram os artistas e vários teóricos convidados, revestindo desta forma um caráter "autorreflexivo", testemunhando do envolvimento dos intervenientes e formalizando o encerramento da iniciativa. o livro que resultou desta experiência não contém apenas os textos dos conferencistas, mas também de alguns artistas. Testemunhos deste género são preciosos para o entendimento da criação, num momento em que a arte contemporânea (prática) tem uma ligação estreita com a filosofia, a estética e as ciências humanas (teoria). As diferentes áreas informam-se umas às outras. Esta dinâmica continua a operar no espaço Lumiar Cité (Alta de Lisboa), associado à Escola Maumaus.

\section{III - Reconstruir o "viver coletivo"?}

Voltemos a Paul Rasse. Num dos capítulos «L'Identité, Enjeu pour Les Musées de Société», o autor traz para a museologia, mais especificamente, para a reflexão sobre os museus de sítio, noções de antropologia de Lévi-Strauss e igualmente da antropologia aplicada às empresas, explicando a importância da noção da identidade no desempenho do indivíduo e da comunidade (esta parte deveria interessar a classe política atual, na necessidade desta de um argumento financeiro no investimento na cultura). De forma muito resumida, Rasse define a identidade como um conceito paradoxal que implica um movimento entre o alter e o ego (Rasse 1997, 22), ou seja, um movimento entre a noção de diferença (eu sou único) e a identificação (eu revejo-me num grupo). Uma definição da identidade da comunidade fortalece desde logo o indivíduo tanto na identificação como na subjacente diferenciação do seu íntimo em relação ao grupo. Estas noções podem ser trazidas para o campo da cultura em geral e da arte contemporânea. E, se Rasse defende que para definir um museu de sítio se deve antes de mais consultar as populações e promover reuniões, inquéritos, conversas, ou seja, de o fazer em conjunto com os principais visados, podemos propor o mesmo ou algo parecido relativamente aos centros de arte contemporânea. Devem-se consultar, convocar e fazer participar os atores da área e as populações locais nestas instituições. Os laços afetivos criados, são desde logo, mais intensos, o que se manifesta por uma frequência e uma participação ativa no centro ou, até mesmo, por uma contribuição importante e benéfica para esses centros e para todas as partes. Mas, mais essencial ainda, porque as pessoas são a principal razão de ser das instituições. Rasse explica como os laços de uma comunidade são desta forma fortalecidos, decorrendo daí uma maior autoconfiança individual e isso repercutir-se-ia na produtividade das pessoas. Sem ir tão longe, pois a noção de "produtividade" é equívoca, podemos deduzir a importância de promover o envolvimento da comunidade artística e da comunidade local nos centros de arte contemporânea. Apesar de algum desalento eventual provocado pelo discurso governativo vigente. A forma de envolver a comunidade pode tomar várias formas, entre as quais formatos modulares como o da Téléthèque. 

dos artistas participantes (Rita Figueiredo com 0 Silêncio de Dois Sons e Cristina Mateus com À Espera), ainda que não fosse de todo um requisito do projeto. Resumindo, a organização deste tipo de ciclos induz o fortalecimento da comunidade e torna o centro de arte contemporânea em algo vivo, em que os encontros, o cruzamento de áreas, a reflexão e a criação acontecem. Nesta experiência viva, o contágio para o resto da comunidade local só pode ser positivo.

Ainda sobre a importância dos encontros ou o formato de conversa, não podemos deixar de invocar Platão, e as suas obras A República (2008) e $O$ Banquete (2008), que constituem a génese da filosofia e da cidadania da cultura ocidental. A reflexão é feita sob forma de diálogo - a reflexão seria por definição dialógica -, em que cada um leva um pouco mais além as problemáticas discutidas, ou contribui para a diversidade dos pontos de vista. Não é novidade, mas é sempre interessante pôr este fator em perspetiva com as novas ferramentas de comunicação, os blogues, por exemplo, em que cada um pode partilhar ou comentar e contribuir, ou as redes sociais, em que a informação é disseminada a grande velocidade, entre grupos de indivíduos que se elegem entre si. Estas ferramentas digitais levar-nos-iam a textos como A República de Platão se não estivessem poluídas com ruído, e se a sua leveza imaterial e o descompromisso dos seus formatos não levassem ao excesso e a uma certa confusão e diluição das ideias, dando lugar à incerteza. Daí, e apesar das ferramentas tecnológicas estarem atualmente disponíveis a "todos", a importância de se desconfiar delas e continuar, ou mesmo, insistir mais ainda nas reuniões presenciais, nos cuidados e nas atenções a ter para que a reflexão e discussão aconteçam. Os formatos digitais não substituem, completam, acrescentam.

Por fim, é inevitável estabelecer o paralelo com os textos considerados subversivos, como Appel (2008) ou A Insurreição que Vem (2010) do Comité Invisible, supostamente sem autor, ou melhor, de autor coletivo (as traduções para as Edições Antipáticas também foram assumidas coletivamente). Nestes textos, é feito um apelo para que as pessoas se organizem entre si, em comunidades: «[...] em França o trabalho feroz e secular de individualização levado a cabo por um poder do Estado que regista, compara, disciplina e separa os seus cidadãos desde a mais tenra idade, que tritura instintivamente as solidariedades que lhe escapam, de modo a que não reste nada senão a cidadania, a pura pertença - fantasmática - à República» (Comité Invisible, 2010, 23). Mais adiante: «Na realidade, a decomposição de todas as formas sociais constitui uma oportunidade inesperada [...] de novos agenciamentos, de novas fidelidades» (Comité Invisible 2010, 31). Assistimos, nos últimos anos, a surtos de revoltas ou de organizações de colectivos por toda a Europa (e não só), no sentido de fazer face a uma situação de crise financeira global e a um sistema capitalista descontrolado (a correr em direção a uma autofagia? Conforme sugerido por Bernard Stiegler $(2006,17):$ «[...] le capitalisme est très profondémment menacé par lui même». Os textos supracitados e estes fatores sociais a que assistimos quotidianamente nos media, quando não à porta de casa, são extremos e sintomáticos interessante matéria para reflexão. Sem irmos tão longe, em última análise, talvez o individualismo na sociedade ocidental tenha de facto atingido o seu cume há muito, fator agravado e simultaneamente esgotado, com as ferramentas tecnológicas e a globalização. Tratar-se-ia talvez agora de, no mínimo, com as liberdades e direitos conquistados, repensar e reconstruir "o viver coletivo"? Fica a sugestão da criação de módulos com maior porosidade em relação à comunidade, para centros de arte contemporânea, sob 
forma de encontros presenciais, para a comunidade artística e abertos ao público - ou a insistência neste tipo de módulos, quando já existem.

\section{Conclusões}

Para concluir, podemos começar por retomar a ideia, talvez um pouco lírica mas real, que a Téléthèque enquanto espaço físico já não existe, mas perdura no (nosso) imaginário como o local que, pelas suas características físicas peculiares, provocou os Encontros Videográficos e os acolheu. Mas só em parte, pois o projeto foi criado com a intenção de proporcionar um espaço de retorno (feedback) para a criação dos artistas (sendo que as conversas eram abertas ao público e apelavam à contribuição deste) e como tentativa de organizar um discurso crítico e inclusivo da diversidade de pontos de vista, e também para suprir dificuldades de memória inerentes às linguagens da arte contemporânea (o efémero e os medias variáveis) e característica dos tempos que correm. Para o contexto museológico, fica o repto: porque não tornar a catalogação de uma obra, num evento coletivo e público no género da Téléthèque? Trata-se também de uma maneira de abrir os centros de arte contemporânea de forma dinâmica, a própria construção do edifício (participação na sua definição e programa), aos seus principais protagonistas e interessados, ou seja, aos artistas vivos e à comunidade local, criando módulos com maior porosidade em relação à comunidade. Os projetos descritos em que, de uma forma ou outra, tal é praticado (“Outros Olhares", "Novos Projetos”, Vídéos et Après, Æther, Pavillon Neufize OBC, Project Room) corroboram a necessidade de tornar o centro de arte contemporânea como um local de encontro, de reflexão e de cruzamento de saberes, sendo sobretudo benéfico para a criação. Mas os benefícios são, na verdade, para toda a sociedade, pela construção de uma ideia de identidade mais forte (coletiva/individual) que se exprime no aumento da sua produtividade.

Existe algo de desumano na invasão do quotidiano pelas novas tecnologias que não se pode deixar de salientar e que o caráter "presencial" destes encontros, no espaço físico dos museus e centros de arte, também vem positivamente contrariar. Conceito sobre o qual também será interessante refletir.

\section{BIBLIOGRAFIA}

Appel. 2008. [Lisboa]: Edições Antipáticas. https://dl.dropboxusercontent.com/u/1929154/ed\%

20an/appel.pdf.

Assche, Christine van. 1992. Vidéo et Après: la Collection Vidéo du Musée National d'Art Moderne. Paris: Centre Pompidou e Carré d'Art.

Baptista, António Alçada. 1988. Catarina ou o Sabor da Maçã. Lisboa: Editorial Presença.

Bénichou, Anne, ed. 2010. Ouvrir le Document: Enjeux et Pratiques de la Documentation dans les Arts Visuels Contemporains. Perceptions. Dijon: Les Presses du Réel. 
Benjamin, Walter. 1992. “A Obra de Arte na Era da sua Reprodutibilidade Técnica.” In Sobre Arte, Técnica, Linguagem e Política. Tradução de Maria Luz Moita. Lisboa: Relógio de Água.

Bock, Jürgen, org. 2002. Da Obra ao Texto: Diálogos sobre a Prática e a Crítica na Arte Contemporânea. Lisboa: Fundação Centro Cultural de Belém.

Buci-Gluksmann, Christine. 2003. Esthétique de l'Éphémère. Collection Écritures/Figures. Paris: Éditions Galilée.

Comité Invisible. A Insurreição que Vem. 2010. Lisboa: Edições Antipáticas.

Deleuze, Gilles. 1980. “Le Lisse et le Strié.” In Mille Plateaux: Capitalisme et Schizophrénie, 592-625. Paris: Éditions de Minuit.

Depocas, Alain, Jon Ippolito, e Caitlin Jones, eds. 2003. L'approche des Médias Variables: la Permanence Par le Changement. Montréal e New York: Fondation. -Daniel Langlois pour l'Art, la Science et la Technologie e The Solomon R. Guggenheim Museum.

Duncan, Carol. 1995. Civilizing Rituals: Inside Public Art Museums. London e New York: Routledge. Gagnier, Richard. 2014. Consultado em fevereiro 18, 2014. www.docam.ca/.

Leccia, Ange. 2011. "Presentation.” Palais de Tokyo. Consultado em abril, 2011. http:// www.palaisdetokyo.com/fr/pavillon/presentation.

Le Nouveau Petit Robert: Dictionnaire Alphabétique et Analogique de la Langue Française. 1993. Paris: Dictionnaires Le Robert.

Marto, Catarina. 2011. "Problemáticas Museológicas do Vídeo na Arte Contemporânea." Dissertação de mestrado em Museologia, Faculdade de Ciências Sociais e Humanas da Universidade Nova de Lisboa. http://hdl.handle.net/10362/7271.

Obrist, Hans Ulrich. 2010. Breve Historia del Comisariado. Colección Ex(it) Libris. Madrid: Exit Publicaciones.

Palais de Tokyo. 2014. "Le Palais de Tokyo." Consultado em fevereiro 18, 2014. http:// www.palaisdetokyo.com/fr/informations-pratiques/le-palais-de-tokyo.

Plataforma Ma. 2010. Téléthèque, Encontros Videográficos. http://teletheque.blogspot.pt.

Platão. 2008. A República. 11. Edição. Tradução de Maria Helena da Rocha Pereira. Lisboa: Fundação Calouste Gulbenkian, Serviço Educação e Bolsas.

Platão. 2008. O Banquete. Tradução de Maria Teresa Schiappa de Azevedo. Clássicos Gregos e Latinos. Lisboa: Edições 70.

Rancière, Jacques. 2008. Le Spectateur Émancipé. Paris: La Fabrique Éditions.

Rasse, Paul. 1997. “L’Identité: Enjeu pour Les Musées de Société.” In Techniques et Cultures au Musée: Enjeux, Ingéniérie et Communication des Musées de Société, 21-54. Muséologies. Lyon: Presses Universitaires de Lyon.

Rouillé, André. 2011. "Pour une Démocratie Esthétique.” Parisart 362. www.paris-art.com/artculture-France/pour-une-democratie-esthetique/rouille-andre/362.html\#haut.

Stiegler, Bernard. 2006. Mécréance et Discrédit. Vol. 2, Les Sociétés Incontrôlables d'Individus Désaffectés. Paris: Éditions Galilée. 


\section{NOTAS}

1. Este artigo resultou da dissertação de mestrado em Museologia Problemáticas Museológicas do Vídeo na Arte Contemporânea, apresentada na Faculdade de Ciências Sociais e Humanas, Universidade Nova de Lisboa (Marto 2011).

2. http://teletheque.blogspot.pt.

3. Veja-se, por exemplo, os seguintes websites sobre conservação de novos medias: Documentation et Conservation du Patrimoine des Arts Médiatiques - Fondation Daniel Langlois (www.docam.ca/ ); Digital Art Conservation (www.digitalartconservation.org/); e Variable Media ( www.variablemedia.net).

4. Veja-se https://www.centrepompidou.fr/cpv/resource/c8EEr8g/rrg8xr5 (consultado em fevereiro 12, 2014).

\section{RESUMOS}

"Téléthèque: Encontros Videográficos" foi um ciclo de visionamento de obras em vídeo e de conversas em torno delas, com a presença dos respetivos autores, que teve lugar no Institut Français du Portugal (Lisboa), em 2010, organizado pela Plataforma Ma. No seguimento da realização deste ciclo, tornou-se evidente que os centros de arte contemporânea poderiam ou deveriam ter um módulo com um desenho parecido ao de Téléthèque. No presente texto começase por explicar muito brevemente em que consistiu e o que motivou este evento. Depois, analisam-se projetos similares ou com características relevantes para refletir sobre as práticas artísticas e curatoriais contemporâneas e, neste contexto, a pertinência e as vantagens que a criação de um módulo deste tipo pode trazer: desde fortalecer uma comunidade artística ao estreitar laços com a comunidade local, a proporcionar espaço para a compreensão e interpretação de ações/obras da arte contemporânea, e ainda como forma de documentação na catalogação de uma obra.

'Téléthèque, Encontros Videográficos' was a video art cycle featuring projections and public talks with their respective authors. It took place approximately once per month throughout the year 2010, at the Institut Français du Portugal (Lisbon) and was organised by Plataforma Ma. Following this cycle, it became clear that the centres of contemporary art could or should have modules with similar characteristics to those of the Téléthèque. This text begins by explaining very briefly what the cycle consisted of and what motivated it. This is followed by a brief observation of similar projects, with characteristics that are relevant to critical thinking on artistic practices and curatorship and, in this context, the relevance and the advantages that this kind of module can bring: starting by the strengthen of an artistic community, forging ties with the local community, to provide space for the understanding and interpretation of actions/works of contemporary art, and also as a way of documenting and cataloguing art works. 


\section{ÍNDICE}

Keywords: contemporary art centre, video art, téléthèque, exhibition, documentation contemporary art

Palavras-chave: centro arte contemporânea, exposição, téléthèque, vídeo arte, documentação arte contemporânea

\section{AUTOR}

\section{CATARINA MARTO}

Licenciada em artes plásticas (Université Paris 8, 2003 - Le Végétal en Tant que Matériau Dans l'Art Contemporain), é mestre em museologia pela Faculdade de Ciências Sociais e Humanas da Universidade Nova com a tese Problemáticas Museológicas do Vídeo na Arte Contemporânea (2012) e frequentou o Independent Study Program da Maumaus - Escola de Artes Visuais. Realizou projetos de curadoria para a Plataforma $\mathrm{Ma}$ (entre outros), escreve no âmbito das artes visuais (Gate Galleries, Ghost book, ed.RE.AL, Embankment) e desenvolve projetos enquanto artista. Entre a teoria e a prática, os seus diferentes interesses levam-na frequentemente a problemáticas em torno da ausência de matéria orgânica na sociedade asséptica e dos ecrãs.

marto.catarina@gmail.com 